\title{
'Catastrophic' healthcare expenditure: critique of a problematic concept and a proposal
}

\author{
Peter Zweifel ${ }^{1}$
}

Published online: 27 January 2016

(C) Springer-Verlag Berlin Heidelberg 2016

At the 2015 World Conference of the International Health Economics Association in Milan, a participant from the European Observatory on Health Systems and Policy presented work that seeks to extend the concept of catastrophic healthcare expenditure (cHCE) from low-income countries to Europe [1]. The authors started from the definition of the World Health Organization (WHO), according to which cHCE is out-of-pocket HCE that pushes down consumption below an estimated poverty line. They noted several shortcomings, causing them to adapt the concept for Europe. This note argues that cHCE has severe shortcomings when applied anywhere.

In an influential contribution, [6] defined cHCE as outof-pocket HCE in excess of capacity to pay (equal to total consumption minus food consumption) by households between the 45 th and 55 th percentile of the 'capacity to pay' distribution. The WHO followed up by publishing a brief on how to design the financing of health care to reduce cHCE [5]. Meanwhile, the cHCE concept has even reached China, with the suggestion that copayments should also be covered by insurance, as though moral hazard simply did not exist in that country [3]. The conclusion for policy in [6] has not changed over the years: "In the long term, the aim should be to develop prepayment mechanisms, such as through social health insurance, tax-based financing of health care, or some mix of prepayment mechanisms". The absence of private health insurance is noteworthy, a detail corrected by [9].

In view of ample health insurance coverage in most European countries, extending the concept of cHCE to

\footnotetext{
Peter Zweifel

peter.zweifel@uzh.ch

Emeritus, University of Zurich, Zurich, Switzerland
}

Europe is a courageous undertaking, to say the least. However, it is flawed even when applied to low-income countries and households. The reason is that individuals manage three assets: as the late Alan Williams [4] aptly called them, Health, Wealth, and Wisdom (meaning human capital in the guise of skills). Two of these assets are analyzed jointly in the Grossman model, which is generally accepted as a cornerstone of health economics [2] (for some reservations in particular about its implementation, see [7]). If one takes this 'asset view' seriously, HCE is a derived decision variable, set to attain a desired stock of health. Therefore, there cannot be anything 'catastrophic' about HCE-unless one surmises that individuals make catastrophic decisions.

One of these decisions is to purchase health insurance coverage (or to exert political pressure by voting for a party that promises to introduce social health insurance for everyone; even the Chinese regime had to expand health insurance coverage beyond urban workers, as mentioned in [3]). However, going without health insurance can be perfectly rational. The price of insurance may simply be too high, causing the law of demand to take effect. Note that the price of insurance is not the premium but the socalled loading for administrative expense and risk bearing because most of the premium flows back to consumers in the guise of benefits paid, at least on expectation. While social health insurance has a lower loading than its private counterpart thanks to an absence of acquisition expense, it tends to be weak at controlling moral hazard. However, moral hazard effects amount to a loading, forcing the insurer to increase contributions in excess of the prevailing expected value of benefits [9].

In addition, private health insurers are almost without exception subject to premium regulation (typically, community rating). This has the unfortunate side effect of 
inducing risk selection. The reason is simple: given community rating, every insurer has enrollees whose (present value of) HCE exceeds the (present value of) contributions. To make up for this deficit, insurers need to have favorable risks in their pool; also, they need to stave off adverse selection, i.e. enrolling too many individuals with high 'catastrophic'! future HCE. Absent premium regulation, high risks would have to pay a high premium (usually as a consequence of experience rating, also known as bonusmalus schemes), while low risks would pay a low premium. This causes expected margins to be equal, making high risks as attractive as low ones. A few countries have introduced risk adjustment as an additional regulation in an attempt to artificially lower the expected marginal cost of enrolling a high risk and to increase it for a low one-with limited success [8]. The much simpler alternative would be to subsidize health insurance contributions for poor households; in this way, their out-of-pocket HCE will be limited to begin with. However, governments have eschewed this transparent solution, preferring to impose the hidden cost of regulation on their citizens.

Having established that going without (private or social) health insurance coverage can be a rational decision, one may now turn to the management of health, wealth, and wisdom in the event of a major health loss. Starting with wisdom, it may make perfect sense to focus on restoring health rather than trying to maintain or even improve skills. Given bad health, investment in skills is likely to have little or no return. Within a household, however, children may be unable to continue their education due to lack of funds caused by HCE. Still, children may consent to spending a great deal of HCE on a parent or sibling if they can expect to benefit from a restoration of their earning power.

Turning to health, making up for a health loss causes wealth to decline as a rule. In keeping with the investment variant of [2], it may make perfect sense to go into debt or accept poverty for a while, provided the HCE has a sufficiently strong effect on the recipient's future labor income. As with all types of investment, this is a risky choice; however, there is nothing 'catastrophic' about it. What is catastrophic is a failure of high $\mathrm{HCE}$ to result in an improvement of health. However, this is a risk that healthcare providers impose on patients-about which the concept of cHCE and the WHO as its proponent are shamefully silent. While the Internet features dozens of items on hospital (nosocomial) infection, inappropriate treatment, and therapeutic failure, the WHO's Institutional Repository for Information Sharing (IRIS) library does not recognize these keywords.

Defining catastrophic HCE in terms of failure to improve health leads to a proposal for its measurement that is straightforward while avoiding an arbitrary percentile cutoff point as in [6]. In the limit, catastrophic HCE results in earlier death, be it through direct effects on health or through indirect effects on wealth and wisdom (little education and low wealth do not foster health, after all). If higher HCE should go along with lower rather than higher remaining life expectancy for any population defined by gender, age, or socioeconomic status, this would constitute evidence of catastrophic HCE indeed. Affaire à suivre for the WHO ....

\section{References}

1. Cylus, J., Vörk, A., Jakab, M., Thomson, S., Eeevetovits, T.: Findings from a new approach to measuring and comparing financial protection in the WHO European region. European Observatory on Health Systems and Policy, London (2005)

2. Grossman, M.: On the concept of health capital and the demand for health. J. Polit. Econ. 80(2), 223-255 (1972)

3. Li, Y., Wu, Q., Legge, D., et al.: Factors affecting catastrophic health expenditure and impoverishment from medical expenses in China: Policy implications for universal health insurance. Bull. World Health Organization 90, 664-671 (2012)

4. Williams, A.H.: '....Makes a man healthy wealthy and wise!' (or from folklore to system science). In Duru, G. et al. (eds.), System Science in Health care. Vol. 2. Paris: Masson (Collection de medicine legale et detoxicologie medicale, No. 139): 57-60 (1988)

5. Xu, K., Evans, D.B., Carrin, G., Aguilar-Rivera, A.M.: Designing health financing systems to reduce catastrophic health expenditure. Technical Brief for Policy-Makers, vol. 2. World Health Organization, Geneva (2005)

6. Xu, K., Evans, D.B., Kawabata, K., et al.: Household catastrophic health expenditure: A multicountry analysis. Lancet 362, 111-117 (2003)

7. Zweifel, P.: The Grossman model after 40 years. Eur. J. Health Econ. 13, 677-682 (2012)

8. Zweifel, P., Frech, H.E.: Why 'optimal' payment for healthcare providers can never be optimal under community rating. Appl. Health Econ. Policy (2016). doi:10.1007/s40258-015-0207-0

9. Zweifel, P., Krey, B.B., Tagli, M.: Supply of private voluntary health insurance in low-income countries. In: Preker, A.S., et al. (eds.) Private voluntary health insurance in development-friend or foe?, pp. 55-113. The World Bank, Washington DC (2007) 